\title{
New fire diurnal cycle characterizations to improve fire radiative energy assessments made from MODIS observations
}

\author{
N. Andela ${ }^{1}$, J. W. Kaiser ${ }^{2}$, G. R. van der Werf ${ }^{1}$, and M. J. Wooster ${ }^{3,4}$ \\ ${ }^{1}$ Faculty of Earth and Life Sciences, VU University, Amsterdam, the Netherlands \\ ${ }^{2}$ Max-Planck-Institut für Chemie, Mainz, Germany \\ ${ }^{3}$ Kings College London, Environmental Monitoring and Modelling Research Group, \\ Department of Geography, London WC2R 2LS, UK \\ ${ }^{4}$ NERC National Centre for Earth Observation (NCEO), UK \\ Correspondence to: N. Andela (niels.andela@nasa.gov)
}

Received: 2 January 2015 - Published in Atmos. Chem. Phys. Discuss.: 31 March 2015

Revised: 17 July 2015 - Accepted: 22 July 2015 - Published: 12 August 2015

\begin{abstract}
Accurate near real time fire emissions estimates are required for air quality forecasts. To date, most approaches are based on satellite-derived estimates of fire radiative power (FRP), which can be converted to fire radiative energy (FRE) which is directly related to fire emissions. Uncertainties in these FRE estimates are often substantial. This is for a large part because the most often used low-Earth orbit satellite-based instruments such as the Moderate Resolution Imaging Spectroradiometer (MODIS) have a relatively poor sampling of the usually pronounced fire diurnal cycle. In this paper we explore the spatial variation of this fire diurnal cycle and its drivers using data from the geostationary Meteosat Spinning Enhanced Visible and Infrared Imager (SEVIRI). In addition, we sampled data from the SEVIRI instrument at MODIS detection opportunities to develop two approaches to estimate hourly FRE based on MODIS active fire detections. The first approach ignored the fire diurnal cycle, assuming persistent fire activity between two MODIS observations, while the second approach combined knowledge on the climatology of the fire diurnal cycle with active fire detections to estimate hourly FRE. The full SEVIRI time series, providing full coverage of the fire diurnal cycle, were used to evaluate the results. Our study period comprised of 3 years (2010-2012), and we focused on Africa and the Mediterranean basin to avoid the use of potentially lower quality SEVIRI data obtained at very far off-nadir view angles. We found that the fire diurnal cycle varies substantially over the study region, and depends on both fuel and weather conditions. For example, more "intense" fires characterized by a
\end{abstract}

fire diurnal cycle with high peak fire activity, long duration over the day, and with nighttime fire activity are most common in areas of large fire size (i.e., large burned area per fire event). These areas are most prevalent in relatively arid regions. Ignoring the fire diurnal cycle generally resulted in an overestimation of FRE, while including information on the climatology of the fire diurnal cycle improved FRE estimates. The approach based on knowledge of the climatology of the fire diurnal cycle also improved distribution of FRE over the day, although only when aggregating model results to coarser spatial and/or temporal scale good correlation was found with the full SEVIRI hourly reference data set. We recommend the use of regionally varying fire diurnal cycle information within the Global Fire Assimilation System (GFAS) used in the Copernicus Atmosphere Monitoring Services, which will improve FRE estimates and may allow for further reconciliation of biomass burning emission estimates from different inventories.

\section{Introduction}

Landscape fires are a global phenomena, and the annually burned area is roughly equivalent to the area of India (Giglio et al., 2013). Most burned area occurs in the savannas of Africa, Australia, and South America, where they shape ecosystem dynamics and due to their scale are an important source of global emissions of (greenhouse) gases and aerosols (Seiler and Crutzen, 1980; Bowman et al., 2009). 
Fires affect air quality both locally and regionally (Langmann et al., 2009), with recent studies putting mortality rates over 300000 annually due to exposure to smoke (Johnston et al., 2012).

Traditionally, the amount of dry matter burned and quantity of trace gases and aerosols emitted have been calculated using biome-specific fire return intervals and estimates of the total amount of biomass as well as the fraction of biomass burned, the combustion completeness (Seiler and Crutzen, 1980). Thanks to new satellite input streams that better capture the spatial and temporal diffuse nature of fires, the estimated fire return intervals have been replaced by direct estimates of monthly, weekly or even daily area burned (Roy et al., 2005; Giglio et al., 2009). In addition, satellite information and biogeochemical modeling have been used to improve estimates of biomass and combustion completeness. However, uncertainties in these bottom-up fire emission estimates are still substantial (Reid et al., 2009; Zhang et al., 2012; Larkin et al., 2014), and they are generally inappropriate for use in near real-time systems partly because the burned area signature is only detectable days to weeks after the actual fire occurrence.

Hot-spot observations from satellites have been used as a proxy for burned area and emissions fluxes in near real time (Freitas et al., 2005; Reid et al., 2009; Wiedinmyer et al., 2011). Another promising and relatively new bottom-up approach uses estimates of fire radiative power (FRP) observed from satellites to calculate daily fire radiative energy (FRE). Wooster et al. (2005) found that these FRE estimates scale directly to dry matter burned, potentially circumventing the uncertainties associated with estimating area burned, fuel loads, and the combustion completeness. In addition, FRP observations can be observed and processed in near real time (Xu et al., 2010; Kaiser et al., 2012; Zhang et al., 2012) and can be measured for small fires that remain undetected in burned area products (Roberts et al., 2011; Randerson et al., 2012).

Hot-spot and FRP observations are currently the only available options when modeling exercises require near real time observations, for example in chemical weather forecasts used to predict air quality. The Global Fire Assimilation System (GFAS; Kaiser et al., 2012), for example, is used to estimate global near real time daily fire emissions within the EUfunded project Monitoring Atmospheric Composition and Climate III (MACC-III). GFAS is currently using fire observations from the polar orbiting Moderate Resolution Imaging Spectroradiometer (MODIS) instruments aboard the Terra and Aqua satellites (Giglio et al., 2006). Due to their relative proximity to the Earth, the Terra and Aqua MODIS instruments have a high sensitivity to even quite low FRP (smaller and/or lower intensity) fires. However, they only provide four daily observations under ideal conditions but less when optically thick clouds are present, which may not be enough to fully characterize how fire activity varies over the course of the day. Observations with a much higher temporal resolution are available from geostationary satellites. However, as a consequence of their geostationary position, these satellites individually do not provide global data and are located at greater distance from the Earth resulting in typically coarser pixel sizes than polar orbiting instruments. Since the threshold of detectability of a fire is not only dependent on the instrument but also a function of the pixel area, geostationary sensors have a higher minimum FRP detection limit (typically $>40 \mathrm{MW})$ than MODIS ( $\sim 8 \mathrm{MW})$. They therefore do not observe the lowest FRP component of the fire regime (Roberts et al., 2005; Freeborn et al., 2014).

Previous studies found that fire activity shows a strong diurnal cycle, and one that is both temporally and spatially variable (Prins and Menzel, 1992; Giglio, 2007; Roberts et al., 2009). The ideal setup to detect fires would be a high temporal resolution imaging system, sensitive to even the lowest FRP fires, and providing global coverage, but due to the limitations of the orbital characteristics outlined above there is no single platform available to provide this. Therefore the estimation of FRE at a global scale is difficult, with polar orbiting satellites lacking observations to accurately represent the fire diurnal cycle and geostationary satellites being limited to certain regions of the globe and omitting the (rather common) low FRP fires. However, previous studies have developed approaches to estimate FRE based on the combination of data from different satellite systems (Boschetti and Roy, 2009; Ellicott et al., 2009; Freeborn et al., 2009, 2011; Vermote et al., 2009).

Some of these mixed approaches used both burned area and active fire data (Boschetti and Roy, 2009; Roberts et al., 2011), which may provide benefits in terms of more accurate FRE determination, but cannot be used easily in near real time systems because of the latency in burned area observations. Alternatively, FRP observations of polar orbiting and geostationary satellites can be blended to combine the sensitivity of the MODIS instruments to lower FRP fires and the diurnal sampling characteristics of SEVIRI. Freeborn et al. (2009) developed a database for matching SEVIRI and MODIS FRP observations based on frequencymagnitude statistics, but the samples had to be accumulated over significant spatial areas $\left(5^{\circ}\right)$ to provide matchable statistics, which is incompatible with the need to develop a method operating at high spatial resolution. Freeborn et al. (2011) later presented an alternative approach, estimating FRE using MODIS data accumulated over 8-day periods over which MODIS samples a location at the fullest range of view zenith angles. The relationship between the "true" FRE and the limited number of FRP samples provided by MODIS was derived using SEVIRI FRP time series sampled at the MODIS sampling interval. Vermote et al. (2009) and Ellicot et al. (2009) used a different approach to create FRE data from MODIS, showing that for several regions of the globe, the fire diurnal cycle can be described by a Gaussian function; they used monthly MODIS data to derive the parameters of the Gaussian. Using this approach, a first global estimation of monthly FRE was made (Ellicott et al., 2009). 
Despite the success of these latter approaches with regard to estimating FRE from MODIS, they are not a solution to the problem posed herein because they require 8 days of consecutive MODIS data and therefore cannot be applied in a near real-time approach.

Global fire emissions estimates at high spatial and temporal resolutions, ideally produced in near real time, are required to feed into atmospheric models which are under continuous development and run at improved resolutions thanks to increased computational power (Zhang et al., 2012). Higher temporal resolution may also help to reconcile bottom-up and top-down emission estimates (Mu et al., 2011). None of the approaches mentioned above are, however, suitable for providing this. Due to these limitations current state of the art global near real time emission inventories still ignore possible effects of fire diurnal cycle on their emission estimates (e.g., Wiedinmyer et al., 2011; Kaiser et al., 2012) and may therefore be structurally biased due to the fire diurnal cycle and the MODIS sampling design (e.g., Ichoku et al., 2008; Ellicott et al., 2009; Freeborn et al., 2011).

The purpose of the work presented here is to better understand the fire diurnal cycle and its spatiotemporal dynamics, in order to develop a new way to include this into a near real time fire emissions estimation framework. First, the spatial distribution and dependencies of the fire diurnal cycle and their effect on active fire detections at MODIS overpasses were explored. Then, data assimilation was used to compare two different methods to derive hourly FRE estimates at $0.1^{\circ}$ resolution based on low Earth-orbiting MODIS observations. The first method ignored the fire diurnal cycle, and was used as a reference to better understand the combined effect of the fire diurnal cycle and the MODIS sampling design on hourly FRE estimates. The second method combined knowledge on the fire diurnal cycle with active fire detections at MODIS overpasses. Following previous studies (Freeborn et al., 2009, 2011), we used FRP observations derived from data collected by the geostationary SEVIRI instrument at MODIS detection opportunities, rather than actual MODIS observations, to drive the two model approaches and we evaluated the model results against the full SEVIRI time series. We used 3 years of active fire data (2010-2012) across Africa and the Mediterranean basin to include a wide range of climates and land cover types, and avoid the use of SEVIRI observations obtained at very far off-nadir angles over South America and northern Europe (Freeborn et al., 2014). Results are intended for application in GFAS within EU's Copernicus Atmosphere Monitoring Service (CAMS, http://atmosphere.copernicus.eu).

\section{Data}

To explore the spatiotemporal dynamics of the fire diurnal cycle, we used hourly temporal resolution FRP data derived from $15 \mathrm{~min}$ observations made by the SEVIRI in- strument hosted onboard the geostationary Meteosat satellite (Sect. 2.1). However, to drive the models developed here we only used SEVIRI FRP observations made at the overpass times of the MODIS polar orbiting sensors (Sect. 2.2), whilst the hourly temporal resolution SEVIRI time series were used to evaluate the results. Land cover characteristics (Sect. 2.3), along with data on fire size (Sect. 2.4), were used to better understand the spatial distribution of fire diurnal cycle. These data sets are described in more detail below, followed by the methods used in Sect. 3.

\subsection{SEVIRI fire radiative power (FRP)}

The SEVIRI instrument aboard the geostationary Meteosat Second Generation (MSG) series of satellites provides coverage of the full Earth disk every $15 \mathrm{~min}$ in 12 spectral bands (Schmetz et al., 2002). The Meteosat SEVIRI FRP-PIXEL product contains per-pixel fire radiative power data along with FRP uncertainty metrics produced from the full spatial and temporal resolution SEVIRI observations (Wooster et al., 2015). The FRP-PIXEL product is produced using an operational version of the geostationary fire thermal anomaly (FTA) algorithm described in Roberts and Wooster (2008), and the product and its performance characteristics are described in Wooster et al. (2015). The FRP-PIXEL products are freely available from the Land Surface Analysis Satellite Applications Facility (LSA SAF; http://landsaf.meteo.pt), from the EUMETSAT EO Portal (https://eoportal.eumetsat. int) or via the EUMETCAST dissemination service (http: //www.eumetsat.int) in both real-time and archived form, as detailed in Wooster et al. (2015). The Meteosat satellites are located at $0^{\circ}$ longitude and latitude, and at nadir the SEVIRI pixels cover $3 \mathrm{~km} \times 3 \mathrm{~km}$ on the ground, but this degrades with increasing view angle away from the West African subsatellite point (Freeborn et al., 2011; Roberts et al., 2015). The FRP-PIXEL product data used here were obtained from the LSA SAF and were rescaled to an hourly $0.1^{\circ}$ resolution with the GFAS gridding algorithm explained in Kaiser et al. (2012). Missing FRP values in individual observations within the hour (e.g., due to smoke or short periods of cloud cover) were thus implicitly ignored. A single $0.1^{\circ}$ grid cell comprises over 13 SEVIRI pixels close to the sub-satellite point (equatorial West Africa), and this reduces to around 6 SEVIRI pixels at greater off-nadir view angles (e.g., Portugal and Madagascar). Data were archived in the Meteorological Archival and Retrieval System (MARS) of the European Centre for Medium-Range Weather Forecasting (ECMWF) prior to their use herein.

\subsection{MODIS detection opportunity}

The two MODIS sensors on board of the Terra and Aqua satellites provide four daily overpasses in most Earth locations, albeit sometimes at view angles in excess of $45^{\circ}$ where the product performance is somewhat degraded (Freeborn 
et al., 2011). At nadir the MODIS thermal channel spatial resolution is $1 \mathrm{~km}$, but decreases away from the swath center (Freeborn et al., 2011). We used the MODIS MOD03 (Terra) and MYD03 (Aqua) geolocation products to determine where and when MODIS data were collected within the SEVIRI Earth disk. As cloud cover may further limit the fire detection opportunity, we used the data quality and cloud cover information of the MOD14 and MYD14 active fire products to filter out grid cells with cloud cover (Giglio et al., 2006). Here we define the detection opportunity as the ability to make unobstructed observations, and the MODIS detection opportunity was derived by combining the MOD03, MYD03, MOD14 and MYD14 products, combining overpass times and cloud cover. We used MODIS data from Collection 5. Like the SEVIRI data, these data were rescaled to hourly $0.1^{\circ}$ resolution with the GFAS gridding algorithm and archived in MARS (Kaiser et al., 2012). The data were archived for the Terra and Aqua satellites separately. The original MODIS swath data can be downloaded from NASA at http://reverb.echo.nasa.gov.

\subsection{MODIS land cover}

The dominant land cover type was derived from the MODIS $\mathrm{MCD} 12 \mathrm{C} 1$ land cover product, which provides $0.05^{\circ} \mathrm{spa}-$ tial resolution annual information on land cover (Friedl et al., 2002). We calculated the dominant land cover type for each grid cell as the land cover type that on average covered the largest fraction during the study period (2010-2012). The University of Maryland (UMD) classification scheme was used, and data were rescaled to $0.1^{\circ}$ resolution. Because we only considered Africa and the Mediterranean basin in this study, and because in some land cover classes very few fires occurred, we could merge some land cover classes that were of relatively little importance for our study. Specifically, all forest classes within the tropics were binned into the tropical forest class, while extratropical forests were all labeled temperate forest. Open and closed shrublands were merged into one shrubland class, and urban and built-up, barren or sparsely vegetated into grasslands.

\subsection{Fire size}

Here we define the fire size for a certain grid cell as the mean burned area per fire event, weighted by their total area burnt (when calculating the mean, a fire event burning $100 \mathrm{~km}^{2}$ is assigned 100 times the weight of an event burning $1 \mathrm{~km}^{2}$ ). The MODIS MCD64A1 burned area product provides daily mapped estimates of global burned area (Giglio et al., 2009). We applied the methods described by Archibald and Roy (2009) to derive a global mean fire "size" (area) map using data over our study period (2010-2012). We made one modification to the approach described by Archibald and Roy (2009): we assumed that two neighboring burned area grid cells only belonged to the same fire if the burn date was no longer than 2 days apart (instead of 8 days). We believe that overall this provides a better estimation of the fire size in our study region, as the vast majority of fires here are grass fires, occurring outside tropical forest zones and thus spreading relatively fast while being relatively less often obstructed by cloud cover. Consequently, the uncertainty in burn date is generally low in our study region (Giglio et al., 2013) and so the 2-day threshold was deemed more appropriate.

\section{Methods}

Our overall goal within GFAS is to provide hourly estimates of FRE at $0.1^{\circ}$ spatial resolution, based on the limited number of MODIS overpasses available each day at each grid cell location. This limited number of daily MODIS observations, in combination with the often pronounced fire diurnal cycle, are the major obstacles in providing the required output. We first studied the spatiotemporal variation of the fire diurnal cycle, in an attempt to understand its variability (Sect. 3.1). Then, we explored the way the fire diurnal cycle affects active fire detections made at the MODIS sampling times (Sect. 3.2). Using this knowledge we explored a new method to parameterize the fire diurnal cycle, and compared results to a modeling approach in which the fire diurnal cycle is ignored. Building on the work of Freeborn et al. $(2009,2011)$, to drive the modeling approaches we used SEVIRI data sampled at the MODIS detection opportunities (according to the hourly data representation introduced above), rather than actual MODIS observations (Sect. 3.2). This allowed us to focus on the issue of diurnal cycle sampling rather than simultaneously dealing with the issue of MODIS and SEVIRI's differential sensitivity to active fires (Freeborn et al., 2009).

Using data assimilation we combined the discrete actual SEVIRI observations, made at the time of the MODIS detection opportunities, with hourly predictions of fire activity using their combination to create continuous hourly best estimate FRE time series (Sect. 3.3). We developed two prediction methods. The first method assumed persistent fire activity until the next satellite detection opportunity, and provides further insights into the combined effect of the fire diurnal cycle and the MODIS sampling design on hourly FRE estimates when the fire diurnal cycle is ignored (Sect. 3.4). The second method followed previous studies and used a Gaussian function to predict fire development over the day (Vermote et al., 2009). By combining prior knowledge about the climatology of the fire diurnal cycle with active fire observations at MODIS overpasses to estimate the parameters of the Gaussian function, this approach provides a possible pathway to implement the fire diurnal cycle into the near real time fire emission modeling framework (Sect. 3.5). Comparing the results of the two approaches to those from the full hourly SEVIRI time series allowed us to determine and discuss their strengths and limitations (Sect. 3.6). 


\subsection{Exploring the fire diurnal cycle}

We started exploring the fire diurnal cycle and its drivers. A Gaussian function was optimally fitted (least squares) to the hourly SEVIRI observations $\widetilde{\rho}_{\mathrm{SEV}(t)}$ for each grid cell and day of fire activity during the study period:

$\tilde{\rho}_{\mathrm{SEV}(t)}=\rho_{\text {base }}+\left(\rho_{\text {peak }}-\rho_{\text {base }}\right) e^{-\frac{\left(h_{t}-h_{\text {peak }}\right)^{2}}{2 \sigma^{2}}}$,

where $\rho_{\text {base }}$ corresponds to the nighttime fire activity, $\rho_{\text {peak }}$ to the maximum FRP for a given day, $\sigma$ is the standard deviation (SD) of FRE distribution over the day (dependent on fire duration), $h_{t}$ is the local solar time at time step $t$ and $h_{\text {peak }}$ is the local hour at which FRP reaches its daily maximum. This resulted in a database containing hourly time series of $\widetilde{\rho}_{\mathrm{SEV}(t)}$ and the fitted Gaussian function, and daily time series of optimal parameter values of the Gaussian function for each grid cell. At the same time we also kept track of hourly MODIS detection opportunities. This enabled us get a better understanding of structural errors caused by the MODIS sampling design in relation to the actual fire diurnal cycle.

Although the fire diurnal cycle as observed by SEVIRI is comparable to that which would be observed by MODIS if it had the same temporal sampling ability, it is a little different due to SEVIRI's inability to discriminate the lowest FRP fire pixels which typically dominate more towards the start and end of the daily fire cycle, but which are also present along with often higher FRP pixels towards the diurnal cycle maxima (Freeborn et al., 2009). To gauge the magnitude of the effect Freeborn et al. (2009) derived the "virtual MODIS" fire product that has the temporal sampling of SEVIRI and the sensitivity to fire of MODIS. They found that the full-width at half maximum height (i.e., the width of the diurnal cycle at half of the daily FRP maximum value) of the diurnal cycles derived from the SEVIRI and the "virtual MODIS" data sets are very similar, it is the amplitude and the full-width at base height of the two cycles, which are more different. In terms of total FRE emitted, the latter is of less importance, here we followed Freeborn et al. (2011) in assuming that the diurnal cycles from SEVIRI and MODIS are sufficiently similar.

In order to visualize the spatial distribution of the fire diurnal cycle, the climatological diurnal cycle was calculated for each grid cell depending on the mean parameter values of the Gaussian function weighted for daily FRE, including all days of fire activity during the study period without cloud obscurance. To get a better understanding of the drivers of the fire diurnal cycle these results were compared to land cover and aspects of the fire regime (fire size, total annual FRE, and the annual number of days with fire activity), see Sect. 2.

\subsection{Sampling SEVIRI data at MODIS detection opportunities}

During the data assimilation, SEVIRI observations at MODIS detection opportunities were used to drive the mod- els. Here, SEVIRI observations for a given hour $t$ are given by $\widetilde{\rho}_{\operatorname{SEV}(t)}$ and SEVIRI fraction of observed area by $\widetilde{\alpha}_{\operatorname{SEV}(t)}$; in the same way, observations of the MODIS instruments are given by $\widetilde{\rho}_{\mathrm{MOD}(t)}$ and $\widetilde{\alpha}_{\mathrm{MOD}(t)}$. Therefore input for the models, i.e., the SEVIRI observations at MODIS detection opportunity times $\left(\widetilde{\rho}_{t}\right.$ and $\left.\widetilde{\alpha}_{t}\right)$ for a given hour $t$ are given by the following:

$\tilde{\rho}_{t}=\widetilde{\rho}_{\mathrm{SEV}}(t)$

$\widetilde{\alpha}_{t}=\widetilde{\alpha}_{\mathrm{MOD}(t)}$.

For clarity, we assumed that the observed FRP $\widetilde{\rho}_{t}$ is zero when there was no MODIS detection opportunity. Anyhow, during the data assimilation $\widetilde{\rho}_{t}$ was weighted for observed area $\widetilde{\alpha}_{t}$, which was zero when there was no observation.

SEVIRI data sampled at MODIS detection opportunities were compared to the full SEVIRI hourly time series to explore the effect of the fire diurnal cycle on the daily sampling at MODIS overpasses. More specifically we calculated the percentage of FRE emitted on days without any active fire detection at MODIS detection opportunities, and the total daily number of MODIS overpasses during the fire season. The latter was calculated by weighing the mean number of monthly detection opportunities at MODIS overpasses by monthly total detected FRP, thus giving the largest weight to the month with most fire activity (ignoring cloud cover).

\subsection{Data assimilation}

We used a modified version the fire data assimilation methodology of GFAS to allow representation of the fire diurnal cycle. GFAS assumes that the availability of observations dominates the error budget of the global FRP fields. It approximates these errors by further assuming the FRP variance to be inversely proportional to the fraction of observed area $\widetilde{\alpha}_{t}$. Thus the variance increases with decreasing partial cloud cover and with the number of satellite observations. In the following data assimilation, GFAS fills observation gaps with a Kalman filter, in which current observations are combined with information from earlier ones. The Kalman filter has a time step of 1 day. It uses a trivial predictive model for the temporal evolution of FRP (i.e., persistence), and assumes for the accuracy of the 1-day FRP prediction that the variance increases by a factor of 9 (Kaiser et al., 2012).

Our modifications affected the step size and the FRP prediction model. The former was set to $1 \mathrm{~h}$ to be able to represent a diurnal cycle. For calculating the FRP prediction $\rho_{t}$, we investigated two different approaches (Sects. 3.4 and 3.5). In both cases, we assumed for the accuracy of the 1h FRP prediction that the variance increases by a factor of 4 . Lowering the value compared to the daily GFAS is motivated by the shorter time step used in our study. However, lowering it too much would not give sufficient weight to new FRP observations. Thus the analysis FRP $\hat{\rho}_{t}$ and "fraction of observed area" $\hat{\alpha}_{t}$ were calculated at each $1 \mathrm{~h}$ time step by optimal 
interpolation as follows, cf. Eqs. (32)-(33) of Kaiser et al. (2012):

$\hat{\rho}_{t}=\frac{1}{\hat{\alpha}_{t}}\left(\frac{\hat{\alpha}_{t-1}}{5} \rho_{t}+\widetilde{\alpha}_{t} \widetilde{\rho}_{t}\right)$

with $\rho_{t}$ according to Sects. 3.4 and 3.5 and

$\hat{\alpha}_{t}=\frac{\hat{\alpha}_{t-1}}{5}+\widetilde{\alpha}_{t}$.

\subsection{Persistent approach}

Applying the daily persistence approach of Kaiser et al. (2012) to hourly time resolution, we first explored the most parsimonious approach that predicts FRP $\rho_{t}$ as being equal to the FRP of the previous time step's analysis:

$\rho_{t}=\hat{\rho}_{t-1}$.

This approach provided insights in the spatiotemporal consequences for FRE estimation when information on the fire diurnal cycle is not incorporated.

\subsection{Climatological approach}

In the second approach we followed previous studies of Vermote et al. (2009) and Ellicot et al. (2009) and the recommendation in Kaiser et al. (2009) to use a Gaussian function to describe a "standard fire diurnal cycle". Wooster et al. (2005) and Roberts et al. (2009) already demonstrated that SEVIRI observations sample the diurnal cycle of large fires well, and for some individual large fires show FRP time series that depict diurnal characteristics appearing close to Gaussian in nature even at 15 min temporal resolution. The prediction was calculated by fitting a Gaussian function through the last $24 \mathrm{~h}$ of analysis:

$\rho_{t}=\rho_{\text {base }}+\left(\rho_{\text {peak }}-\rho_{\text {base }}\right) e^{-\frac{\left(h_{t}-h_{\text {pak }}\right)^{2}}{2 \sigma^{2}}}$.

However, only $h_{\text {peak }}$ was optimally fitted, by minimizing the sum of least squares between the Gaussian function and the previous $24 \mathrm{~h}$ of the analysis:

$\hat{\rho}_{t-24}, \hat{\rho}_{t-23}, \ldots, \hat{\rho}_{t-1}$.

Following previous studies that found that fire diurnal cycle is land cover dependent (Giglio, 2007; Roberts et al., 2009; Vermote et al., 2009; Freeborn et al., 2011), we used land cover (LC) average values $\sigma_{\mathrm{LC}}$ for $\sigma$ (weighted by FRE). Values of $\rho_{\text {base }}$ and $\rho_{\text {peak }}$ on the other hand could be directly related to daily MODIS observations. We followed Vermote et al. (2009) to use the mean of the nighttime (defined here as 6.00 p.m. -6.00 a.m. local time the next day) observations at MODIS detection opportunities to determine $\rho_{\text {base }}$. To relate SEVIRI observations at MODIS detection opportunities to $\rho_{\text {peak }}$ the ratio of mean daytime (6.00 a.m.-6.00 p.m.)
FRP observations at MODIS detection opportunities to mean $\rho_{\text {peak }}$ was calculated per land cover type. We used per land cover average values for scaling the daytime observations at MODIS detection opportunities to $\rho_{\text {peak }}$ rather than the values found per grid cell to keep the model generic and globally applicable. Finally, if there were no active fires observed during the previous $24 \mathrm{~h}$, we forced the prediction to be zero, to prevent fires from continuing during long periods of no observations.

\subsection{Model evaluation}

The estimated hourly FRE fields (or analysis; $\hat{\rho}_{t}$ ) resulting from the two modeling approaches (persistent and climatological) were evaluated via comparison to those derived from the hourly SEVIRI time series (see Sect. 2.1). Two criteria were used to evaluate model performance: first, the spatial distribution of FRE estimates; and second, the temporal distribution of FRE. The spatial performance of the modeling approaches was assessed via their ability to reproduce the annual mean FRE per land cover type, and by comparing the spatial distribution of FRE as estimated by the modeling approaches and as derived from SEVIRI over the study region and period. The temporal performance was assessed via the ability of the model to allocate the emitted energy in the right grid cell at the right moment in time. Here we used Pearson's $r$ between the modeled and observed (SEVIRI) FRE time series at four different spatiotemporal resolutions $\left(0.1^{\circ}\right.$ and $1^{\circ}$ spatial, and hourly and daily temporal resolution). Each spatiotemporal scale provides unique information on the model performance. Correlation coefficients at hourly resolution depend on the ability of the model to estimate the distribution of fire activity over the day, while daily aggregated estimates provide insights in the ability to get overall budgets right. In a similar way, the two spatial resolutions provide information on the ability of the model to resolve high-resolution distribution of fire activity and more regional model performance. When calculating Pearson's $r$ between the hourly model results and SEVIRI data, we included cloud-free days only, while the daily model results were compared to the full cloud cover corrected SEVIRI times series, using a simple cloud cover correction method explained below.

Finally, we compared daily regional aggregated FRE time series for several study regions of the two modeling approaches and SEVIRI. In order to compare daily regional time series to the model, a cloud cover correction needed to be carried out. Since persistent cloud cover is relatively rare during the burning season in most parts of Africa, we chose a simple gap-filling approach where the value of the last cloud-free observation is assumed to be valid until the next cloud-free observation, which is consistent with the observation gap filling in the daily GFAS. 

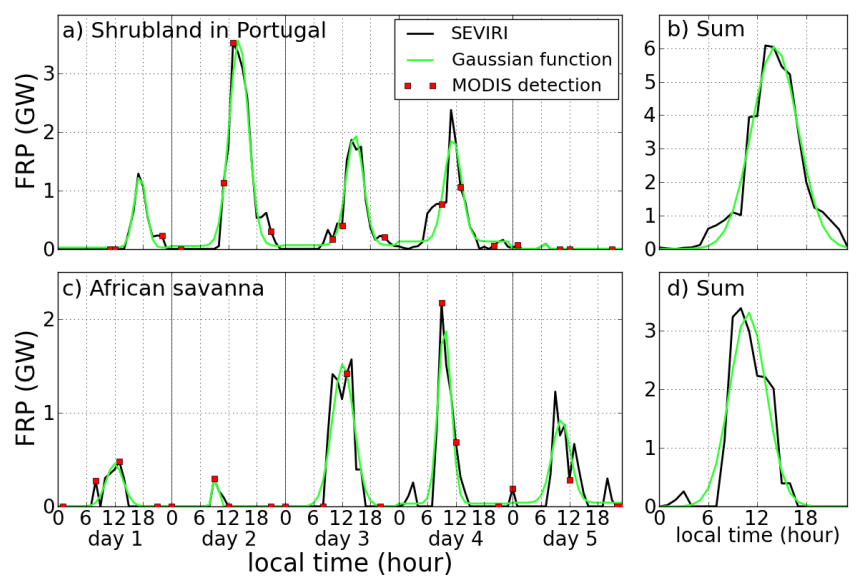

Figure 1. Hourly-mean FRP time series derived from SEVIRI data, the same data but only sampled at MODIS detection opportunities, and an optimally fitted Gaussian function fitted to the full SEVIRI FRP time series. These two examples are for a $0.1^{\circ}$ shrubland grid cell in Portugal $(\mathbf{a}, \mathbf{b})$ and a $0.1^{\circ}$ savanna grid cell in Africa (c, d). $(\mathbf{a}, \mathbf{c})$ represent the hourly time series and $(\mathbf{b}, \mathbf{d})$ the aggregated fire diurnal cycle over the 5 study days. Time is indicated as local time.

\section{Results}

\subsection{The diurnal cycle and MODIS sampling}

First, we present the results related to the spatial distribution of the fire diurnal cycle, and assess the impact of the fire diurnal cycle on active fire observations made at times of MODIS overpasses. The spatial distribution of the fire diurnal cycle was explored by optimally fitting a Gaussian function to the hourly, $0.1^{\circ}$ SEVIRI FRP time series. Reasonable overall correlations between SEVIRI and the optimally fitted Gaussian functions were found (Pearson's $r=0.55$; weighted mean for all grid cells), while a Gaussian was better able to describe hourly fire activity in regions where fires could spread over large areas and were characterized by high $\rho_{\text {peak }}$ (e.g., for fire size $<10 \mathrm{~km}^{2} r=0.51$, for $10-50 \mathrm{~km}^{2}$ $r=0.56$, and $>50 \mathrm{~km}^{2} r=0.63$ ). This is likely to be in part related to the fact that characterization of the diurnal cycle of "smaller" fires will be more affected by instances of SEVIRI failing to detect one or more of their fire pixels than would larger fires, hence introducing more variability into the apparent diurnal cycle. Whilst the SEVIRI FRP-PIXEL product shows apparently the best performance metrics of any current geostationary fire product derived from SEVIRI data (Baldassarre et al., 2015), such failures in active fire pixel detection clearly occur, for example simply due to fire pixels being too low in their FRP to detect by SEVIRI, along with a variety of potential other factors (Wooster et al., 2015).

Figure 1 shows an example of two $0.1^{\circ}$ grid cells in which the hourly average FRP maxima reached relatively high levels, well in excess of $1 \mathrm{GW}$, and fire persisted for several days. As with the individual fires, shown by SEVIRI in
Wooster et al. (2005) and Roberts et al. (2009), the FRP from these fires appears to drop to zero, or near zero, every night. This is a consequence both of the actual FRP from the fire significantly diminishing at this time due to, for example, fuel moisture, wind and other ambient atmospheric conditions being far less conducive to intense fire activity by night than by day (Hély et al., 2003; Gambiza et al., 2005), but also because some fire pixels will have FRPs below the SEVIRI active fire pixel detection limit of around $40 \mathrm{MW}$ (Roberts and Wooster, 2008). At the start of the following day, fuel moisture and ambient atmospheric conditions generally become more conducive to fire, and fire intensities and rates of spread typically increase once more such that more of the fire-affected pixels breach the SEVIRI FRP detection limit (Roberts et al., 2009).

The results shown in Fig. 1 indicate that high FRP, relatively long-lived fire activity is rather well described by a Gaussian function, even at this $0.1^{\circ}$, hourly resolution which is significantly higher than that used in previous studies fitting Gaussian descriptors to remotely sensed measures of active fire activity. At the same time, it also became apparent that observations from a MODIS-type sampling interval are not always representative of the daily fire activity. The inability of the MODIS sampling times to provide representative observations is well illustrated in Fig. 1a, where on the first day of the fire the morning and afternoon time of MODIS sampling slot almost completely missed the fire activity.

The shape of the Gaussian function, and consequently the parameters: SD $(\sigma)$ peak fire activity $\left(\rho_{\text {peak }}\right)$ and corresponding hour $\left(h_{\text {peak }}\right)$, varied considerably over the individual days (Fig. 1). For example, in the African savanna grid cell (Fig. 1c), fire activity on day 3 continued for longer in the afternoon compared to day 4 , when conditions some-how became less favorable for maintaining the fire earlier in the afternoon. Therefore, the shape of the fire diurnal cycle is dependent on spatiotemporal scale. When diurnal fire activity was aggregated over several days, which can be compared to using a coarser temporal or spatial resolution, $\sigma$ increased as compared to fire activity for individual days (compare Fig. 1a with $b$, and Fig. 1c with d). The relatively narrow diurnal cycle of the individual days have varying peak hours of fire activity, so that the sum of it is wider than any of the individual cycles and the peak fire activity less pronounced.

In addition to an observed variability in the fire diurnal cycle seen on different days, we found distinct spatial patterns in the optimal fitted Gaussian parameters (Fig. 2). Some of these patterns were similar for the different parameters. In particular, there were zones of generally more intense fires (e.g., South Sudan, northern Central African Republic, Botswana, Namibia and parts of Angola and the Democratic Republic of Congo (DRC)), showing relatively high values of $\rho_{\text {peak }}, \rho_{\text {base }}$ and $\sigma$ compared to other zones where values for all three parameters were relatively low (e.g., Zambia, Mozambique, Tanzania, Nigeria and Cameroon). On top of this general pattern, a clear gradient is visible as you move 

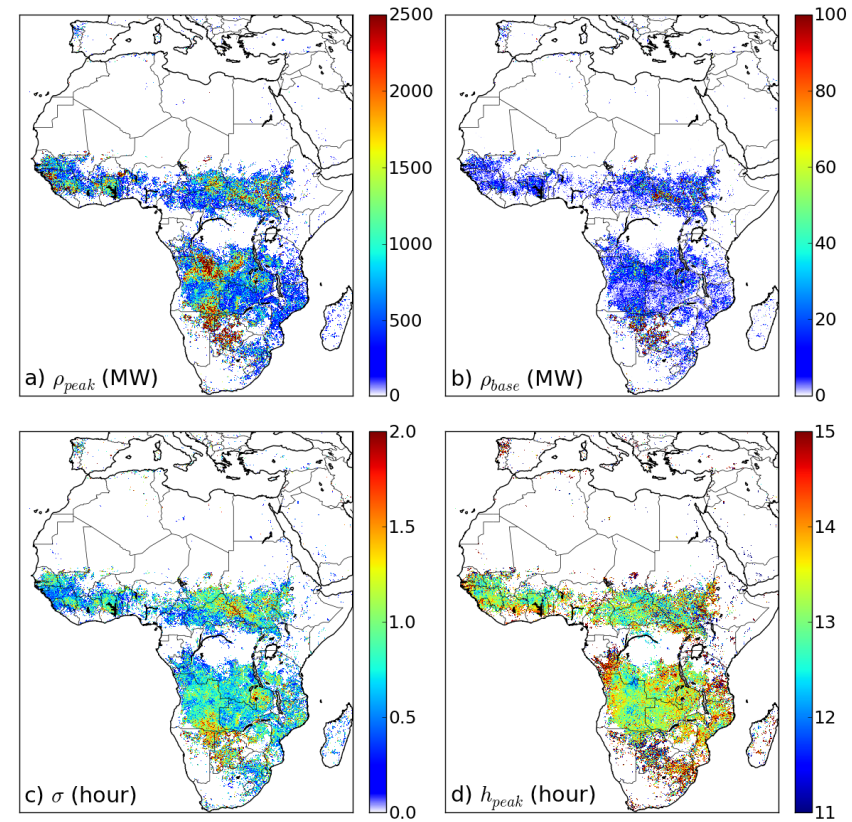

Figure 2. Weighted mean values of parameters of the optimally fitted Gaussian function for each $0.1^{\circ}$ grid cell, including all cloudfree days during the study period. (a) Peak daytime FRP $\rho_{\text {peak }}$; (b) night time FRP $\rho_{\text {base }}$; (c) SD of the FRE distribution over the day $\sigma$ (related to the fire duration over the day, or width of the diurnal cycle); and (d) hour of peak fire activity $h_{\text {peak }}$ (local time). Grid cells with emitted energy below $5 \mathrm{MJ}$ over the study period (approximately the FRE emitted during one small fire event) were excluded from the figure to facilitate interpretation.

from drier to more humid regions, seen most clearly when moving from Namibia via Angola to DRC. In more humid savannas, when fuel conditions were optimal, high $\rho_{\text {peak }}$ values could be reached but fire duration over the day was generally short and night time FRP values were more likely to fall below the SEVIRI FRP detection threshold (Fig. 2). $h_{\text {peak }}$ varied considerably over the study region, with areas showing most fire activity late in the afternoon generally in more humid or forested regions but also in some more arid regions (Fig. 2d).

Table 1 shows the land cover-averaged values and SD of the results presented in Fig. 2. In addition we calculated the ratio of the mean SEVIRI FRP at MODIS daytime detection opportunities to the maximum daytime FRP $\rho_{\text {peak }}$. These results were used in the climatological modeling approach that combined the fire diurnal cycle climatology with observations made at the MODIS sampling times to derive the daily fire diurnal cycle predictions (Sect. 3.5). More intense fires with long duration and high peak values were associated with fires in shrublands, savannas and grasslands, while a more pronounced fire diurnal cycle was present in more humid woody savannas or tropical forests. For $\sigma, \rho_{\text {peak }}$ and $\rho_{\text {base }}$ SD was typically about half of the average value, while SD of $h_{\text {peak }}$ was largest for temperate forests, shrublands and grass-
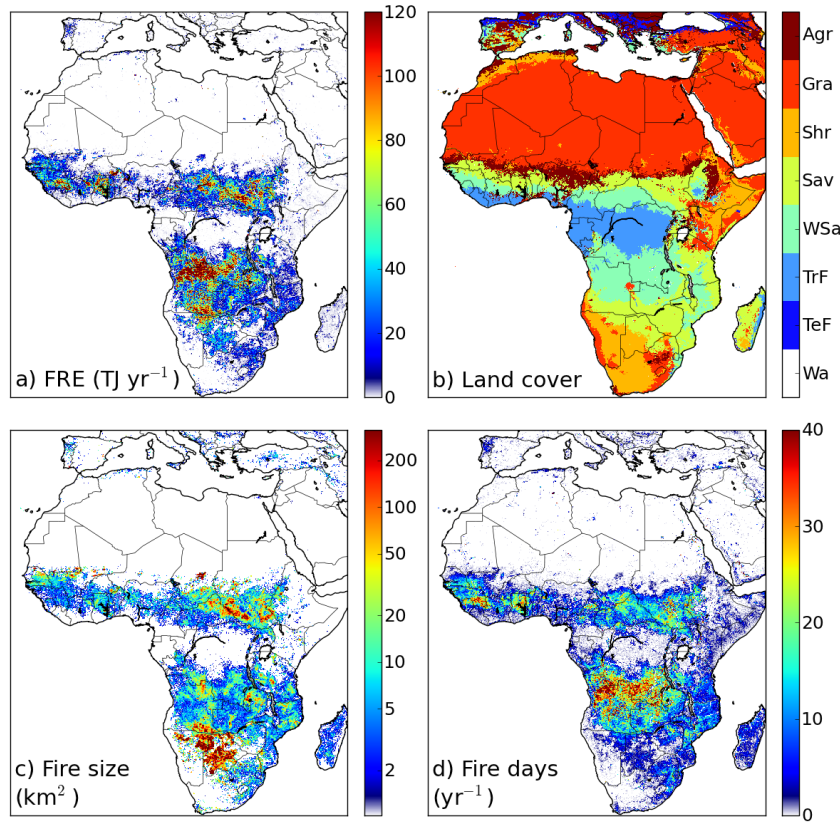

Figure 3. Characteristics of the fire regime and fuel types based on 2010-2012 data. (a) Mean annual FRE per $0.1^{\circ}$ grid cell; (b) dominant land cover type; (c) fire size (i.e., weighted mean burned area per fire event); and (d) mean annual number of days with fire activity per grid cell over the study period. Abbreviations of land cover classes: water (Wa), temperate forest $(\mathrm{TeF})$, tropical forest $(\mathrm{TrF})$, woody savanna (WSa), savanna (Sav), shrubland (Shr), grassland (Gra) and agriculture (Agr).

lands. The ratio of mean daytime FRP made at the MODIS sampling times and $\rho_{\text {peak }}$ was relatively constant for various land cover types with $\rho_{\text {peak }}$ generally about 3 times as large as the mean FRP at the daytime MODIS detection opportunities (Table 1).

In order to better understand the spatial distribution of the fire diurnal cycle features, we studied characteristics of the fire regime that were expected to be related to fuel properties and the diurnal cycle (Fig. 3a, c and d). To guide the interpretation we have included a land cover map, partly governing fuel loads, in Fig. 3b. Annual emitted FRE varied widely over the study region, and highest values were found in the savannas and woody savannas (compare Fig. 3a with b) and coincided with regions of large fire size and/or a high number of annual fire days (compare Fig. 3a with c and d). Similarities with characteristics of the fire diurnal cycle were also found, the earlier mentioned zones of generally more intense fires (high values of $\rho_{\text {peak }}, \rho_{\text {base }}$ and $\sigma$ ) often coincided with regions of large fire size (Figs. $2 \mathrm{a}-\mathrm{c}$ and $3 \mathrm{c}$ ). In the more humid tropical areas, high $\rho_{\text {peak }}$ values occurred in areas of relatively large fire size and/or a high number of annual fire days (Figs. $2 \mathrm{a}$ and $3 \mathrm{c}, \mathrm{d}$ ).

The relative fraction of FRE emitted on days that SEVIRI data sampled at MODIS observation times did not observe 
Table 1. Mean values of the parameters of the Gaussian function per land cover type (excluding days of cloud cover and weighted by FRE), SD are shown in parenthesis. Values of $\sigma$ and the ratio of $\rho_{\text {peak }}$ and mean day-time FRP at MODIS detection opportunities (MODIS mean $_{\text {) }}$ were used within the climatological approach to model hourly FRP (see Sect. 3.5).

\begin{tabular}{lccccc}
\hline Land cover & $\begin{array}{c}\sigma \\
\text { (hour) }\end{array}$ & $\begin{array}{c}\rho_{\text {peak }} \\
(\mathrm{MW})\end{array}$ & $\begin{array}{c}\rho_{\text {base }} \\
(\mathrm{MW})\end{array}$ & $\begin{array}{c}h_{\text {peak }} \\
(\text { hour })\end{array}$ & $\begin{array}{c}\rho_{\text {peak }} / \text { MODIS } \\
(-)\end{array}$ \\
\hline Temperate forest & $1.14(0.55)$ & $846(392)$ & $24.2(12.7)$ & $13.31(4.50)$ & 3.17 \\
Tropical forest & $0.85(0.45)$ & $1364(863)$ & $27.3(19.6)$ & $13.34(2.57)$ & 3.03 \\
Woody savanna & $0.94(0.50)$ & $1501(934)$ & $21.1(16.8)$ & $13.21(2.08)$ & 3.07 \\
Savanna & $1.09(0.53)$ & $1711(899)$ & $39.0(25.5)$ & $13.08(2.58)$ & 2.88 \\
Shrubland & $1.35(0.63)$ & $3079(1552)$ & $108.9(56.9)$ & $13.16(4.46)$ & 2.87 \\
Grassland & $1.06(0.53)$ & $1642(863)$ & $37.3(21.1)$ & $12.95(4.44)$ & 3.08 \\
Cropland & $0.95(0.48)$ & $1259(705)$ & $23.9(16.0)$ & $13.33(3.22)$ & 2.94 \\
\hline
\end{tabular}
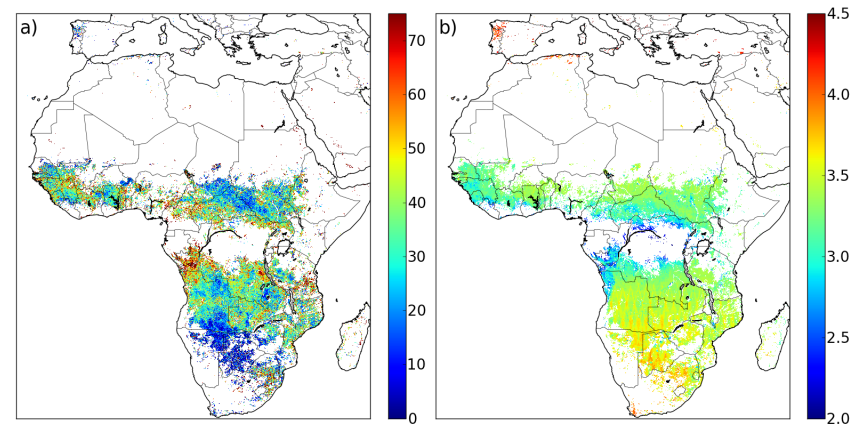

Figure 4. Detection of fire activity at MODIS detection opportunities. (a) Percentage of FRE emitted on days that the SEVIRI instrument did not observe active fires at MODIS overpasses. (b) Number of MODIS detection opportunities per day during the burning season (mean over the study period, weighted for monthly FRP).

active fires is an important factor affecting model performance, and showed similar spatial patterns as $\sigma$, indicating that duration of fires over the day plays an important role (Figs. 2c and 4a). In addition, the geographical location and cloud cover during the burning season played a role by affecting the effective number of daily MODIS observations (Fig. 4b). The peak hour of fire activity also played a role, and especially in more humid areas with frequent cloud cover and late afternoon fire activity sometimes over $50 \%$ of FRE was emitted on days without any SEVIRI active fire detections at MODIS detection opportunities (compare Figs. 2d and $4 \mathrm{a}$ ). The most important biomass burning regions were typically characterized by relatively long fire duration over the day (Fig. 2c) and the effect of omission of active fires on continental scale FRE estimates was therefore relatively low (cf. Figs. 3a, 4a and 5). However, frequent omission of relatively small fires of short duration may strongly affect FRE estimates for some regions (Fig. 5). These results clearly demonstrate the value of the data provided by the very high temporal resolution geostationary systems, even though they are unable to resolve and detect fire pixels as low in FRP as those from polar orbiters (Roberts and Wooster, 2008).
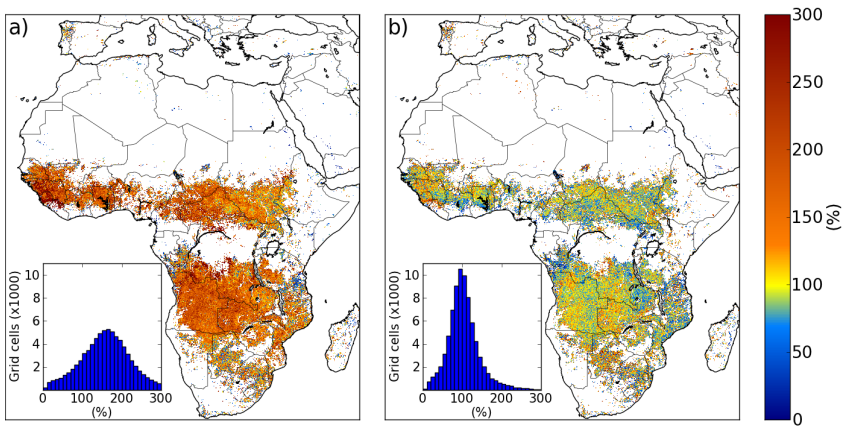

Figure 5. Total fire radiative energy (FRE) estimated via the two modeling approaches using SEVIRI observations taken at only the MODIS detection opportunities, expressed as fraction of the total FRE calculated using the entire set of hourly mean, $0.1^{\circ}$ SEVIRI FRP observations (cloud cover corrected). (a) Persistent approach, and (b) climatological approach. Distribution of the grid cell values is shown in the lower left corners.

\subsection{Model evaluation}

To evaluate the two modeling approaches that estimated FRE from SEVIRI data only at the MODIS sampling times we started with comparing the spatial distribution of mean estimated FRE for each method with the cloud corrected SEVIRI FRE calculated using the entire hourly, $0.1^{\circ}$ SEVIRI FRP data set (Fig. 5). The persistent approach resulted in a general overestimation of FRE, while the climatological approach showed overall good performance in terms of total estimated FRE when compared to the full SEVIRI data set. Moreover, the more narrow distribution of modeled FRE as a fraction of SEVIRI FRE by the climatological approach as opposed to the persistent approach suggests that results are not only more accurate but also more precise (Fig. 5). While this reflects the general pattern, the performance bias was not homogeneous over the region. The persistent approach showed best results for regions with long daytime fire durations (i.e., large $\sigma$ ) and with a late peak in fire activity; and although performing generally better, the climatological 

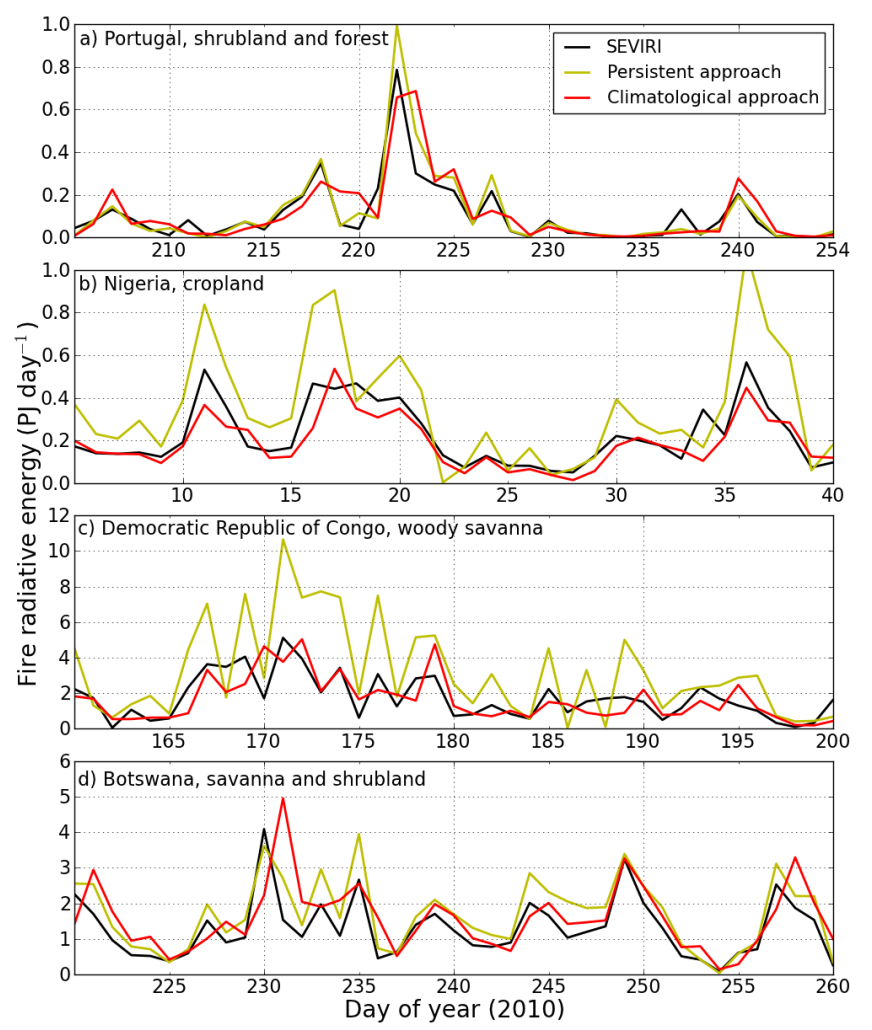

Figure 6. Daily FRE for four study regions (areas of 85000 to $567000 \mathrm{~km}^{2}$ ) derived from the complete SEVIRI data set (cloud cover corrected) and estimated by the two modeling approaches developed here. (a) Daily FRE for Portugal, mostly including shrublands and temperate forests, (b) fires in Nigeria burning in croplands, (c) woody savannas in DRC, and (d) shrublands and savannas in Botswana. Study regions are shown in Fig. 7, and land cover was determined using the dominant land cover classes (Sect. 2.3; Fig. 3b).

approach showed a general underestimation for areas of relatively late peak fire activity (compare Figs. 2 and 5). To a certain extent these regional differences correspond to the distribution of the different land cover types (Table 2). For example, for temperate forests and shrublands the persistent modeling approach showed notably better comparison to the FRE derived via the entire SEVIRI data set, while the climatological modeling approach overestimated FRE.

Equally important as the absolute FRE estimates shown in Fig. 5 and Table 2 are their temporal dynamics. Figure 6 shows regional daily budgets for several study regions with different geographical positions and land cover (see Fig. 7). Similar to the results in Fig. 5, we found a general overestimation by the persistent approach, and better overall estimation by the climatological approach. Overestimation of the persistent approach was occurring mostly in the tropics (e.g., Nigeria and DRC), where also stronger day-to-day variability was observed as compared to that derived with the complete SEVIRI data or the climatological approach (Fig. 5).
Table 2. Estimated annual FRE during 2010-2012 by the two model approaches as percentage of SEVIRI FRE (cloud cover corrected).

\begin{tabular}{lrrr}
\hline Land cover & $\begin{array}{r}\text { SEVIRI } \\
\left(\mathrm{PJ} \mathrm{yr}^{-1}\right)\end{array}$ & $\begin{array}{r}\text { Persistent } \\
(\%)\end{array}$ & $\begin{array}{r}\text { Climatological } \\
(\%)\end{array}$ \\
\hline Temperate forest & 2.9 & 98 & 118 \\
Tropical forest & 61.3 & 179 & 98 \\
Woody savanna & 1513.2 & 174 & 93 \\
Savanna & 990.7 & 155 & 99 \\
Shrubland & 91.7 & 120 & 115 \\
Grassland & 106.5 & 125 & 108 \\
Cropland & 74.5 & 147 & 90 \\
Total & 2841.9 & 163 & 97 \\
\hline
\end{tabular}

The climatological approach showed a small delay in FRE estimations compared to the complete SEVIRI data set.

To further test the ability of the two modeling approaches to allocate FRE to the individual grid cells at the right moment in time, correlation coefficients were calculated. Table 3 shows Pearson's $r$ between SEVIRI and the two modeling approaches at four spatiotemporal resolutions $\left(0.1^{\circ}\right.$ and $1^{\circ}$ spatial and hourly and daily temporal resolution). A striking increase in correlation was observed when aggregating model results both temporally or spatially. Freeborn et al. $(2009,2011)$ previously demonstrated the value of such spatial aggregation when deriving relationships between SEVIRI and MODIS data sets, and this technique is currently used within the near real-time SEVIRI FRP-GRID products produced by the LSA SAF from the SEVIRI FRP-PIXEL data (Wooster et al., 2015). At $0.1^{\circ}$ resolution the best correlations were found for shrublands and savannas, while for aggregated data best performance was found for woody savannas and savannas. At hourly resolution, the climatological approach generally performed better than the persistent approach. However, at $0.1^{\circ}$ daily resolution the persistent approach performed best, while at $1^{\circ}$ daily resolution the persistent and climatological approaches did equally well.

\section{Discussion}

Unlike biomass burning emission inventories based on burned area, inventories using active fire observations from Earth observation satellites can be produced in near real time (Freitas et al., 2005; Reid et al., 2009; Sofiev et al., 2009; Wiedinmyer et al., 2011; Kaiser et al., 2012; Darmenov and da Silva, 2013). The near real time emissions inventories are, at present, generally based on active fire data from the MODIS instruments operating onboard the Terra and Aqua polar orbiting satellites. The FRP observations of MODIS are almost without saturation, operating day and night, with a reasonable spatial resolution and with new observations available for any location at least a few times every day cloud cover permitting. However, it is well known that fire 
Table 3. Pearson's $r$ between hourly and daily FRE as observed by SEVIRI and estimated by the two modeling approaches. Correlation is calculated for two spatial scales, the original $0.1^{\circ}$ resolution and a $1^{\circ}$ aggregated resolution (in parentheses) to test regional model performance.

\begin{tabular}{lcccc}
\hline Land cover & $\begin{array}{c}\text { Persistent } \\
\text { hourly }\end{array}$ & $\begin{array}{c}\text { Climatological } \\
\text { hourly }\end{array}$ & $\begin{array}{c}\text { Persistent } \\
\text { daily }\end{array}$ & $\begin{array}{c}\text { Climatological } \\
\text { daily }\end{array}$ \\
\hline Temperate forest & $0.24(0.33)$ & $0.20(0.32)$ & $0.44(0.50)$ & $0.21(0.39)$ \\
Tropical forest & $0.13(0.25)$ & $0.15(0.27)$ & $0.32(0.41)$ & $0.16(0.41)$ \\
Woody savanna & $0.19(0.44)$ & $0.20(0.52)$ & $0.48(0.80)$ & $0.25(0.79)$ \\
Savanna & $0.25(0.45)$ & $0.25(0.51)$ & $0.54(0.78)$ & $0.30(0.76)$ \\
Shrubland & $0.35(0.47)$ & $0.32(0.47)$ & $0.61(0.63)$ & $0.37(0.60)$ \\
Grassland & $0.22(0.32)$ & $0.20(0.35)$ & $0.46(0.55)$ & $0.22(0.52)$ \\
Cropland & $0.19(0.32)$ & $0.17(0.36)$ & $0.42(0.61)$ & $0.18(0.60)$ \\
Total & $0.22(0.43)$ & $0.22(0.50)$ & $0.50(0.76)$ & $0.27(0.75)$ \\
\hline
\end{tabular}

activity in most regions follows a clear daily cycle (e.g., Roberts et al., 2009; Vermote et al., 2009). Consequently, the FRP measures derived from intermittent polar orbiting MODIS observations are often not fully and directly representative of the actual daily fire activity (Fig. 1; Giglio, 2007; Vermote et al., 2009; Freeborn et al., 2011). Although several approaches have been developed to obtain more accurate estimations of FRE from the limited temporal sampling of FRP provided by MODIS (e.g., Ellicott et al., 2009; Freeborn et al., 2009, 2011; Vermote et al., 2009), they are all best suited to be used with previously collected and/or aggregated FRP data, and none can be readily implemented at high spatiotemporal resolution in near real time. For this reason, most current global emission inventories produced in near real time actually ignore fire diurnal dynamics completely (e.g., Kaiser et al., 2012), and this results in large biases in the FRE budgets (Ellicott et al., 2009; Zhang et al., 2012).

Here we start discussing the spatial distribution of the fire diurnal cycle, and its drivers (Sect. 5.1). Building on previous work, we explored two new methods to estimate hourly FRE in near real time from observations made by SEVIRI at MODIS detection opportunities. The results illustrate how MODIS observations might be used to calculate hourly FRE, and where errors can be expected due to the diurnal cycle and the limited temporal sampling provided by MODIS (Sect. 5.2).

\subsection{Exploring the fire diurnal cycle using a Gaussian function}

The fire diurnal cycle characteristics were explored by fitting of a Gaussian function to the hourly SEVIRI time series. Vermote et al. (2009) and Ellicott et al. (2009) found that at a $0.5^{\circ}$ monthly resolution the fire diurnal cycle can be described by a Gaussian function, using MODIS observations to resolve the unknown parameters. They choose the spatiotemporal size of the study regions such that a statistical representative number of fires and MODIS FRP detections were included, and the observations covered the full range

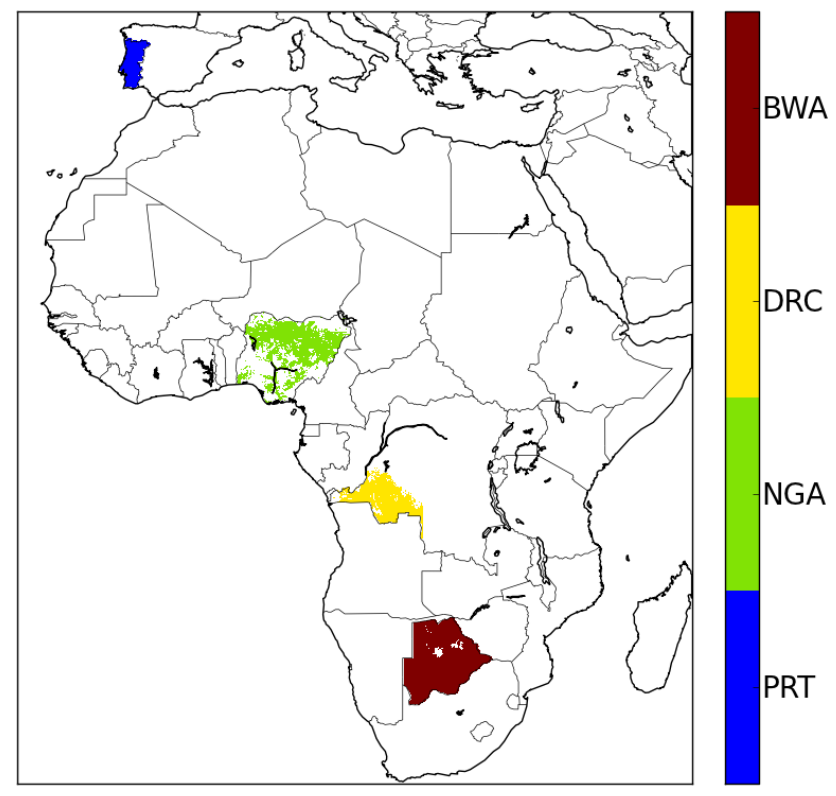

Figure 7. Study regions used in Fig. 6. Abbreviations refer to: Botswana (BWA), the Democratic Republic of Congo (DRC), Nigeria (NGA) and Portugal (PRT).

of MODIS view angles - since the sensitivity of MODIS to fire depends upon this (Vermote et al., 2009). Although later work showed that in fact fire activity may be somewhat skewed in the afternoon, here we found that even at a high spatiotemporal resolution $\left(0.1^{\circ}\right.$; hourly), a Gaussian function provides a fairly robust description of the fire diurnal cycle. However, at $0.1^{\circ}$ hourly resolution, SEVIRI data sampled at the MODIS detection opportunities does not always provide enough information to adequately depict fire activity for an individual grid cell and day (Fig. 1). Moreover, the spatiotemporal scale at which we observe the fire diurnal cycle has a significant impact on its shape. When moving to a coarser spatiotemporal resolution, the shape of the diurnal cycle likely becomes wider, with less pronounced peaks. 
This is mostly a consequence of the spatiotemporal variation in hour of peak fire activity of the individual fires or fire days (Fig. 1). Therefore, typical values of the parameters of the Gaussian found in this study (Fig. 2) do not necessarily correspond to typical values found by earlier studies (e.g., Roberts et al., 2009; Vermote et al., 2009), who used much larger sample sizes (i.e., spatiotemporal resolutions). Likewise the results presented here are not necessarily representative for individual fires.

Although the shape of the "average" fire diurnal cycle is scale dependent, regional patterns in the diurnal cycle characteristics (Fig. 2) remain similar over different scales, and therefore we found similar land cover dependent characteristics as previous studies. For example, shrublands and grasslands generally faced drier conditions when burning than did woody savannas or tropical forest, and therefore fire activity typically continued longer over the day and the hour of peak fire activity was generally located later in the afternoon (Fig. 2; Table 1; Giglio, 2007; Roberts et al., 2009). For the same reason, temperate and boreal forests have been reported to show a more pronounced diurnal cycle than grasslands (Fig. 2; Sofiev et al., 2013; Konovalov et al., 2014). Building on the land cover based analysis of Roberts et al. (2009), we provide a first analysis of the spatial distribution of the fire diurnal cycle.

The three parameters determining the shape of the Gaussian can be used to visualize the spatial distribution of the fire diurnal cycle. The daily FRP-maximum is given by $\rho_{\text {peak }}$, fire duration over the day by $\sigma$, and the baseline FRP by $\rho_{\text {base }}$. Similar spatial patterns were found for all three parameters mentioned above (Fig. 2a, b and c). This indicates that there are zones of generally more "intense" fires with high $\rho_{\text {peak }}$, large $\sigma$ and higher $\rho_{\text {base }}$, while other zones are characterized by lower intensity fires. In land cover classes where most of the fires were grass-fueled (grasslands, savannas and woody savannas), a considerable part of the spatial variation in fire diurnal cycle could be explained by fire size (see Sect. 2.4; Figs. 2 and 3). Large fires were often found in frequently burnt and/or more arid areas (Fig. 3a) where high fuel connectivity, low fuel density and low fuel moisture allow relatively fast moving fires with large fire fronts to form (Hély et al., 2003; Sow et al., 2013). Besides fire size and land cover, part of the variability in the fire diurnal cycle could be explained by a gradient in diurnal weather conditions. Grass-fueled large fires were also common in the more humid savannas of southern Africa, but here nighttime weather conditions appear to become rather unfavorable for fire (Figs. 2b and 3c). In humid savannas $\rho_{\text {peak }}$ values were not solely associated with large fire size, but also with areas showing a high number of annual days with fire activity and may be explained by several relatively small fires burning at the time. The high number of fire days may indicate a larger number of fire ignitions and/or that fires are spreading at a slower rate due to the more pronounced fire diurnal cycle, higher humidity, or higher fuel density (Hély et al.,
2003; Sow et al., 2013). Finally, in the Mediterranean basin the relatively low fire return period, and consequently higher fuel density, may also cause relative intense fires with long duration over the day (Fig. 2; Archibald et al., 2013).

The peak hour of fire activity found here corresponds to the moment of day at which $50 \%$ of the total FRE has been emitted (assuming $\rho_{\text {base }} \ll \rho_{\text {peak }}$ ), and it did not always correspond to the peak hour of fire activity found by previous studies (Fig. 2d; e.g., Giglio, 2007; Roberts et al., 2009; Vermote et al., 2009). In general most FRE was emitted during the afternoon, and clear spatial patterns were present in the typical peak hour of the Gaussian. High values of $h_{\text {peak }}$ were found in regions of higher fuel density or in more arid areas where fires could spread over large areas (Figs. 2d and 3). In arid regions with large typical fire sizes, fire spread was often fast and a $0.1^{\circ}$ grid cell only corresponded to a part of the actual fire resulting in large variation in $h_{\text {peak }}$ between neighboring grid cells (Fig. 2d and Table 1).

\subsection{Model performance and the MODIS sampling design}

Data assimilation and two modeling approaches, were used to estimate hourly FRE from SEVIRI FRP data sampled at the times of MODIS detection opportunities. Here we start discussing the performance of the different methods with respect to their total FRE estimates and daily regional FRE estimations. Then we discuss the more uncertain model performance at higher spatiotemporal resolutions.

The persistent approach is comparable to a direct hourly extension of the current GFAS methods (Kaiser et al., 2012), where the fire diurnal cycle is ignored and the predicted FRP for each hour is equal to that of the last FRP observation. This led to a general overestimation of daily FRE because the 13:30 LT temporal sampling time of MODIS is relatively close to the peak hour of daily fire activity, and therefore not very representative of the full period until the next observation at 22:30 LT (Figs. 2d and 5; Table 2). Moving away from the equator, the number of daily MODIS observations increases due to orbital convergence at higher latitudes, and consequently the model performance improved (Figs. $4 \mathrm{~b}, 5$ and 6; Giglio et al., 2006; Reid et al., 2009). Additional inclusion of daytime observations due to orbital convergence will typically be somewhat earlier or later in the afternoon and may therefore lower the FRE estimation. In the persistent approach, missing nighttime observations may cause an overestimation and missing daytime observation an underestimation of daily FRE, resulting in erroneous regional dayto-day variations in FRE estimates in the tropics (Fig. 6). Following previous research, we found that due to the spatiotemporal variation of the fire diurnal cycle FRE was overestimated more for some land cover types than for others (Table 2; Freeborn et al., 2011). Land cover classes that typically showed longer fire durations (Fig. 2c) with peak fire activity later in the afternoon (Fig. 2d) were not as much overesti- 
mated as land cover classes with more pronounced fire diurnal cycles (Figs. 5 and 6; Table 2). However, part of this effect likely stems from these land covers mostly being located in the more frequently observed higher latitudes of our study region. Although the persistent method is not directly comparable to the methods of widely used emission inventories like GFAS or QFED (Quick Fire Emissions Dataset) (Kaiser et al., 2012; Darmenov and da Silva, 2013), they likely introduce similar errors by ignoring the fire diurnal cycle.

The climatological approach showed better performance in terms of absolute FRE estimations, while also better able to reproduce its spatial variability (Fig. 5). In contrast to the persistent approach, the hourly predictions were based on the last $24 \mathrm{~h}$ of fire activity, enabling more realistic gap filling during periods without observations. This resulted in an advantage during periods of cloud cover or missing observations due to the satellite orbits, but because of the low number of actual daily observations the climatological approach had the tendency to continue predicting fire activity after fires had ceased, seen as a small delay in the signals in Fig. 6.

An additional criterion to evaluate the model performance was the correlation between the modeling approaches and the SEVIRI data at different spatiotemporal scales. Correlation between the modeled and SEVIRI time series improved considerably when moving from hourly to daily resolution, showing that the models were better able to estimate daily budgets than the distribution of fire activity over the day. These differences may be explained by the inability of the models to correctly estimate the hour of peak fire activity, a fire diurnal cycle that is not well represented by a Gaussian function, or in the case of small fires the fire diurnal cycle may not be fully detected by the SEVIRI instrument. Because of the large day-to-day variation in the fire diurnal cycle and the FRP measurements limited to the time of the MODIS overpasses, the individual FRP observations have a low precision (i.e., large random error) and omission (i.e., non detection) of fires is frequent (Figs. 1 and 4), resulting in low correlation at high spatiotemporal scales (Table 3). Because fires rarely occur on their own and generally form part of a regional pattern (Bella et al., 2006), the correlation increased considerably when accumulating results to a $1^{\circ}$ spatial scale. For the same reason model performance was found to be best in savannas and woody savannas, where the highest number of fires occur and the sample size is thus largest, or in areas of large fire size where omission was relatively low. Model performance was therefore best when optimal burning conditions were reached, often coinciding with the peak of the burning season. Because often only a reasonably large sample of observations made at the MODIS detection opportunities is actually representative of fire activity in a certain region, the added value of the $0.1^{\circ}$ spatial resolution (e.g., GFASv1.1/1.2) is somewhat limited compared to a coarser $0.5^{\circ}$ spatial resolution (e.g., GFASv1.0).

Overall, using the climatological approach resulted in the best model performance, although in specific cases using the persistent approach showed better results. For example, at $0.1^{\circ}$ spatial and daily temporal resolution the persistent approach performed best, likely because it only predicts fire activity on days of actual fires while the climatological approach may predict fire activity with some delay. Also the climatological approach used mean values for the fire duration and may therefore overestimate FRE from smaller fires while underestimating the larger fires. Despite the improved results of the climatological approach as opposed to the persistent approach, estimating FRE in near real time based on MODIS observations remains challenging, especially at high spatiotemporal resolutions. Largest uncertainties originate from the high spatiotemporal variability of the fire diurnal cycle combined with the limited number of daily MODIS detection opportunities. Moreover, the fire diurnal cycle as analyzed here may to some extent be affected by the inability of SEVIRI to detect the smallest fires, along with other sources of uncertainty in the FRP observations (Wooster et al., 2015; Roberts et al., 2015). Finally, the characterization of the fire diurnal cycle and discussion of its spatiotemporal drivers presented here provide a first step to upscale the climatological model to a global scale, but a better understanding of the fire diurnal cycle and its drivers for other regions of the globe remains an important issue.

Within GFAS, to handle the uncertainties introduced into the MODIS-derived FRE estimates by neglecting the diurnal cycle influence, the estimated FRE is converted into estimates of dry matter burned (DM) using land cover-specific conversion factors. These were derived via comparison of long-term monthly FRE estimates to the DM estimates calculated over the same period by the Global Fire Emissions Database (GFED 3.1; van der Werf et al., 2010; Kaiser et al., 2012). It is currently assumed that by allowing the conversion factors to vary with land cover type the impact of any land cover-varying diurnal cycle is also incorporated, reducing the influence of the diurnal cycle. The issues discussed above, along with the accuracy of the GFED DM calculations, which are for example affected by the quality of the burned area product and the biochemical models used, all influence values of the land cover-specific FRE-to-DM conversions factors presented by Kaiser et al. (2012).

Wooster et al. (2005) and Freeborn et al. (2008) previously explored the conversion factors between FRE and DM using small scale experiments, and found that they appeared relatively independent of vegetation type. However, when moving to the satellite-scale there are additional factors influencing this FRE-to-DM relationship, for example the fire regime of an area and the degree to which MODIS misses the lowest FRP fires, and the canopy density of trees that might obscure some of the thermal radiation being emitted by fires burning in the ground fuels (Freeborn et al., 2014). The thermal radiation recorded in satellite products is additionally reduced by cloud cover and erroneous flagging of smoke as clouds during data processing. Konovalov et al. (2014) nevertheless found FRE-to-DM relationships relatively similar 
to those of the earlier small-scale experiments when using atmospheric observations and biomass burning trace gas and aerosol emissions factors to estimate fuel consumption. Exploring methods to incorporate the fire diurnal cycle in the GFAS global FRP-based near real time emission inventory is a first step in taking into account some of these issues in order to improve global FRE estimates made at relatively high spatiotemporal resolutions, and hopefully also in reconciling some of the differences in current emission inventories.

\section{Conclusions}

Emission inventories based on FRP observations have great potential to improve biomass burning emission estimates, by eliminating the need for modeling of fuel loads and fuel consumption, and can be produced in near real time. However, to date uncertainties in FRE estimates remain high when using polar orbiting FRP data sets, largely due to difficulties in combining the limited temporal resolution observations and knowledge about the fire diurnal cycle. Geostationary data can alleviate this issue, but bring their own problems related to the non-detection of the lower FRP fires due to the coarse spatial resolution of the geostationary observations. Geostationary data sets are also not global in extent. Here we explored the spatial dependencies of the fire diurnal cycle and its impact on active fire detections made at the time of MODIS overpasses. Two modeling approaches were developed to derive hourly FRE estimates based on dataassimilation and SEVIRI FRP observations subsampled at MODIS detection opportunities. The first approach ignored the fire diurnal cycle assuming persistent fire activity between two MODIS detection opportunities, while the second approach combined prior knowledge of the fire diurnal cycle with active fire observations at MODIS detection opportunities to simulate the fire diurnal cycle. Both approaches were evaluated against the actual hourly FRP observations made by SEVIRI. Our main conclusions are the following.

1. We considered various drivers of the spatial distribution of fire diurnal cycle (dominant land cover, fire size, annual number of fire days, and diurnal climate conditions) and found that all played a role. The strong relation between fire size and fire diurnal cycle for grassfueled fires, and the climatic gradient in diurnal cycle, indicate that using fuel characteristics rather than land cover alone to characterize the fire diurnal cycle provides a potential pathway to improve these estimates. Here we showed that this information can partly be obtained by studying the fire characteristics, such as fire size, which are contained within the remote sensing data themselves.

2. Ignoring the fire diurnal cycle may cause structural errors in FRE estimates, and likely results in a general overestimation of FRE due to the timing of the MODIS overpasses. The errors vary regionally, mostly due to variations in the fire diurnal cycle, while results get more accurate at higher latitudes due to the increasing number of daily MODIS detection opportunities caused by orbital convergence.

3. Due to the large day-to-day variations in the fire diurnal cycle at the grid cell level, and the scarce number of MODIS observations of any one location per day, daily FRP fields calculated from observations made at MODIS detection opportunities are characterized by low precision (i.e., observations are not representative for daily fire activity) and high omission (i.e., non observation of fires). Therefore a sufficiently large sample size of MODIS observations is required to accurately estimate FRE, as shown earlier by Freeborn et al. (2011). In zones of frequent fires, where fires are generally part of a regional biomass burning pattern, model performance greatly improved when moving to a coarser scale, increasing the sample size. Model performance was also considerably better for zones of relatively large fires that were characterized by low omission. Production of emission inventories at very high spatiotemporal resolution using data from a limited number of low-Earth orbit satellite observations may therefore provide somewhat restricted added value compared to those derived at coarser spatiotemporal scales.

4. Relative overrepresentation of day- or nighttime FRP observations may cause large day-to-day variations in estimated FRE when the diurnal cycle is ignored.

5. The way we observe the fire diurnal cycle is scale dependent, mostly because of the large variation in fire diurnal cycle, even within the same grid cell between different days.

We recommend implementing the climatological model within GFAS in Copernicus Atmosphere Services in order to improve global and regional FRE estimates and further reconcile emission estimates from the various different inventories currently available.

Acknowledgements. We like to thank Samuel Remy at ECMWF for processing MODIS and SEVIRI data, and the data providing agencies: NASA and the EUMETSAT LSA SAF for making their data publicly available. This study was funded by the EU in the FP7 and H2020 projects MACC-II and MACC-III (contracts no. 283576 and 633080).

Edited by: R. Engelen 


\section{References}

Archibald, S. and Roy, D. P.: Identifying individual fires from satellite-derived burned area data, IEEE Int. Geosci. Remote Sens. Symp. Proc., 9, 160-163, 2009.

Archibald, S., Lehmann, C. E. R., Gómez-Dans, J. L., and Bradstock, R. A.: Defining pyromes and global syndromes of fire regimes, P. Natl. Acad. Sci. USA, 110, 6442-6447, 2013.

Baldassarre, G., Pozzoli, L., Schmidt, C. C., Unal, A., Kindap, T., Menzel, W. P., Whitburn, S., Coheur, P.-F., Kavgaci, A., and Kaiser, J. W.: Using SEVIRI fire observations to drive smoke plumes in the CMAQ air quality model: a case study over Antalya in 2008, Atmos. Chem. Phys., 15, 8539-8558, doi:10.5194/acp-15-8539-2015, 2015

Bella, C. M., Jobbagy, E. G., Paruelo, J. M., and Pinnock, S.: Continental fire density patterns in South America, Global Ecol. Biogeogr., 15, 192-199, 2006.

Boschetti, L. and Roy, D. P.: Strategies for the fusion of satellite fire radiative power with burned area data for fire radiative energy derivation, J. Geophys. Res., 114, D20302, doi:10.1029/2008JD011645, 2009.

Bowman, D. M. J. S., Balch, J. K., Artaxo, P., Bond, W. J., Carlson, J. M., Cochrane, M. A., D’Antonio, C. M., Defries, R. S., Doyle, J. C., Harrison, S. P., Johnston, F. H., Keeley, J. E., Krawchuk, M. A., Kull, C. A., Marston, J. B., Moritz, M. A., Prentice, I. C., Roos, C. I., Scott, A. C., Swetnam, T. W., van der Werf, G. R., and Pyne, S. J.: Fire in the Earth system, Science, 324, 481-484, 2009.

Darmenov, A. S. and da Silva, A.: The Quick Fire Emissions Dataset (QFED) - Documentation of Versions 2.1, 2.2 and 2.4, NASA Tech. Rep. Ser. Glob. Model. Data Assim., Greenbelt, USA, 32 pp., 2013.

Ellicott, E., Vermote, E., Giglio, L., and Roberts, G.: Estimating biomass consumed from fire using MODIS FRE, Geophys. Res. Lett., 36, L13401, doi:10.1029/2009GL038581, 2009.

Freeborn, P. H., Wooster, M. J., Hao, W. M., Ryan, C. A., Nordgren, B. L., Baker, S. P., and Ichoku, C.: Relationships between energy release, fuel mass loss, and trace gas and aerosol emissions during laboratory biomass fires, J. Geophys. Res., 113, D01301, doi:10.1029/2007JD008679, 2008.

Freeborn, P. H., Wooster, M. J., Roberts, G., Malamud, B. D., and $\mathrm{Xu}, \mathrm{W}$.: Development of a virtual active fire product for Africa through a synthesis of geostationary and polar orbiting satellite data, Remote Sens. Environ., 113, 1700-1711, 2009.

Freeborn, P. H., Wooster, M. J., and Roberts, G.: Addressing the spatiotemporal sampling design of MODIS to provide estimates of the fire radiative energy emitted from Africa, Remote Sens. Environ., 115, 475-489, 2011.

Freeborn, P. H., Wooster, M. J., Roberts, G., and Xu, W.: Evaluating the SEVIRI fire thermal anomaly detection algorithm across the Central African Republic using the MODIS active fire product, Remote Sens. Environ., 6, 1890-1917, 2014.

Freitas, S. R., Longo, K. M., Silva Dias, M. A. F., Silva Dias, P. L., Chatfield, R., Prins, E., Artaxo, P., Grell, G. A., and Recuero, F. S.: Monitoring the transport of biomass burning emissions in South America, Environ. Fluid Mech., 5, 135-167, 2005.

Friedl, M. A., McIver, D. K., Hodges, J. C. F., Zhang, X. Y., Muchoney, D., Strahler, A. H., Woodcock, C. E., Gopal, S., Schneider, A., Cooper, A., Baccini, A., Gao, F., and Schaaf, C.: Global land cover mapping from MODIS: algorithms and early results, Remote Sens. Environ., 83, 287-302, 2002.

Gambiza, J., Campbell, B. M., Moe, S. R., and Frost, P. G. H.: Fire behaviour in a semi-arid Baikiaea plurijuga savanna woodland on Kalahari sands in western Zimbabwe, S. Afr. J. Sci., 101, 239244, 2005.

Giglio, L.: Characterization of the tropical diurnal fire cycle using VIRS and MODIS observations, Remote Sens. Environ., 108, 407-421, 2007.

Giglio, L., Justice, C. O., and Csiszar, I.: Global distribution and seasonality of active fires as observed with the Terra and Aqua Moderate Resolution Imaging Spectroradiometer (MODIS) sensors, J. Geophys. Res., 111, G02016, doi:10.1029/2005JG000142, 2006.

Giglio, L., Loboda, T., Roy, D. P., Quayle, B., and Justice, C. O.: An active-fire based burned area mapping algorithm for the MODIS sensor, Remote Sens. Environ., 113, 408-420, 2009.

Giglio, L., Randerson, J. T., and van der Werf, G. R.: Analysis of daily, monthly, and annual burned area using the fourthgeneration global fire emissions database (GFED4), J. Geophys. Res.-Biogeo., 118, 317-328, 2013.

Hély, C., Alleaume, S., Swap, R. J., Shugart, H. H., and Justice, C. O.: SAFARI-2000 characterization of fuels, fire behavior, combustion completeness, and emissions from experimental burns in infertile grass savannas in western Zambia, J. Arid Environ., 54, 381-394, 2003.

Ichoku, C., Giglio, L., Wooster, M. J., and Remer, L. A.: Global characterization of biomass-burning patterns using satellite measurements of fire radiative energy, Remote Sens. Environ., 112, 2950-2962, 2008.

Johnston, F. H., Henderson, S. B., Chen, Y., Randerson, J. T., Marlier, M., Defries, R. S., Kinney, P., Bowman, D. M. J. S., and Brauer, M.: Estimated global mortality attributable to smoke from landscape fires, Environ. Health Persp., 120, 695-701, 2012.

Kaiser, J. W., Flemming, J., Schultz, M. G., Suttie, M., and Wooster, M. J.: The MACC Global Fire Assimilation System: First Emission Products (GFASv0), Tech. Memo. 596, ECMWF, Reading, UK, 2009.

Kaiser, J. W., Heil, A., Andreae, M. O., Benedetti, A., Chubarova, N., Jones, L., Morcrette, J.-J., Razinger, M., Schultz, M. G., Suttie, M., and van der Werf, G. R.: Biomass burning emissions estimated with a global fire assimilation system based on observed fire radiative power, Biogeosciences, 9, 527-554, doi:10.5194/bg-9-527-2012, 2012.

Konovalov, I. B., Berezin, E. V., Ciais, P., Broquet, G., Beekmann, M., Hadji-Lazaro, J., Cler-baux, C., Andreae, M. O., Kaiser, J. W., and Schulze, E.-D.: Constraining $\mathrm{CO}_{2}$ emissions from open biomass burning by satellite observations of co-emitted species: a method and its application to wildfires in Siberia, Atmos. Chem. Phys., 14, 10383-10410, doi:10.5194/acp-14-10383-2014, 2014.

Langmann, B., Duncan, B., Textor, C., Trentmann, J., and van der Werf, G. R.: Vegetation fire emissions and their impact on air pollution and climate, Atmos. Environ., 43, 107-116, 2009.

Larkin, N. K., Rause, S. M., and Strand, T. M.: Wildland fire emissions, carbon, and climate: US emissions inventories, Forest Ecol. Manag., 317, 61-69, , 2014.

Mu, M., Randerson, J. T., van der Werf, G. R., Giglio, L., Kasibhatla, P., Morton, D. C., Collatz, G. J., DeFries, R. S., Hyer, E. 
J., Prins, E. M., Grith, D. W. T., Wunch, D., Toon, G. C., Sherlock, V., and Wennberg, P. O.: Daily and 3 hourly variability in global fire emissions and consequences for atmospheric model predictions of carbon monoxide, J. Geophys. Res.-Atmos., 116, D24303, doi:10.1029/2011JD016245, 2011.

Prins, E. M. and Menzel, W. P.: Geostationary satellite detection of biomass burning in South America, Int. J. Remote Sens., 13, 2783-2799, 1992.

Randerson, J. T., Chen, Y., van der Werf, G. R., Rogers, B. M., and Morton, D. C.: Global burned area and biomass burning emissions from small fires, J. Geophys. Res., 117, G04012, doi:10.1029/2012JG002128, 2012.

Reid, J. S., Hyer, E. J., Prins, E. M., Westphal, D. L., Zhang, J., Wang, J., Christopher, S. A., Curtis, C. A., Schmidt, C. C., Eleuterio, D. P., Richardson, K. A., and Homan, J. P.: Global monitoring and forecasting of biomass-burning smoke: description of and lessons from the Fire Locating and Modeling of Burning Emissions (FLAMBE) program, IEEE J. Sel. Top. Appl., 2, 144-162, 2009.

Roberts, G. J. and Wooster, M. J.: Fire detection and fire characterization over Africa using meteosat SEVIRI, IEEE T. Geosci. Remote, 46, 1200-1218, 2008.

Roberts, G., Wooster, M. J., Perry, G. L. W., Drake, N., Rebelo, L.-M., and Dipotso, F.: Retrieval of biomass combustion rates and totals from fire radiative power observations: application to southern Africa using geostationary SEVIRI imagery, J. Geophys. Res., 110, D21111, doi:10.1029/2005JD006018, 2005.

Roberts, G., Wooster, M. J., and Lagoudakis, E.: Annual and diurnal african biomass burning temporal dynamics, Biogeosciences, 6 , 849-866, 2009,

http://www.biogeosciences.net/6/849/2009/.

Roberts, G., Wooster, M. J., Freeborn, P. H., and Xu, W.: Integration of geostationary FRP and polar-orbiter burned area datasets for an enhanced biomass burning inventory, Remote Sens. Environ., 115, 2047-2061, 2011.

Roberts, G., Wooster, M. J., Xu, W., Freeborn, P. H., Morcrette, J.-J., Jones, L., Benedetti, A., and Kaiser, J. W.: Meteosat SEVIRI Fire Radiative Power (FRP) products from the Land Surface Analysis Satellite Applications Facility (LSA SAF) - Part 2: Product evaluation and demonstration of use within the Copernicus Atmosphere Monitoring Service, Atmos. Chem. Phys. Discuss., 15, 15909-15976, doi:10.5194/acpd-15-15909-2015, 2015.

Roy, D. P., Jin, Y., Lewis, P. E., and Justice, C. O.: Prototyping a global algorithm for systematic fire-affected area mapping using MODIS time series data, Remote Sens. Environ., 97, 137-162, 2005.

Schmetz, J., Pili, P., Tjemkes, S., Just, D., Kerkmann, J., Rota, S., and Ratier, A.: An introduction to Meteosat Second Generation (MSG), B. Am. Meteorol. Soc., 83, 977-991, 2002.

Seiler, W., and Crutzen, P. J.: Estimates of gross and net fluxes of carbon between the biosphere and the atmosphere from biomass burning, Climatic Change, 2, 207-247, 1980.
Sofiev, M., Vankevich, R., Lotjonen, M., Prank, M., Petukhov, V., Ermakova, T., Koskinen, J., and Kukkonen, J.: An operational system for the assimilation of the satellite information on wildland fires for the needs of air quality modelling and forecasting, Atmos. Chem. Phys., 9, 6833-6847, doi:10.5194/acp-9-68332009, 2009.

Sofiev, M., Vankevich, R., Ermakova, T., and Hakkarainen, J.: Global mapping of maximum emission heights and resulting vertical profiles of wildfire emissions, Atmos. Chem. Phys., 13, 7039-7052, doi:10.5194/acp-13-7039-2013, 2013.

Sow, M., Hély, C., Mbow, C., and Sambou, B.: Fuel and fire behavior analysis for early-season prescribed fire planning in Sudanian and Sahelian savannas, J. Arid Environ., 89, 84-93, 2013.

van der Werf, G. R., Randerson, J. T., Giglio, L., Collatz, G. J., Mu, M., Kasibhatla, P. S., Morton, D. C., DeFries, R. S., Jin, Y., and van Leeuwen, T. T.: Global fire emissions and the contribution of deforestation, savanna, forest, agricultural, and peat fires (19972009), Atmos. Chem. Phys., 10, 11707-11735, doi:10.5194/acp10-11707-2010, 2010.

Vermote, E., Ellicott, E., Dubovik, O., Lapyonok, T., Chin, M., Giglio, L., and Roberts, G. J.: An approach to estimate global biomass burning emissions of organic and black carbon from MODIS fire radiative power, J. Geophys. Res., 114, D18205, doi:10.1029/2008JD011188, 2009.

Wiedinmyer, C., Akagi, S. K., Yokelson, R. J., Emmons, L. K., AlSaadi, J. A., Orlando, J. J., and Soja, A. J.: The Fire INventory from NCAR (FINN): a high resolution global model to estimate the emissions from open burning, Geosci. Model Dev., 4, 625641, doi:10.5194/gmd-4-625-2011, 2011.

Wooster, M. J., Roberts, G., Perry, G. L. W., and Kaufman, Y. J.: Retrieval of biomass combustion rates and totals from fire radiative power observations: FRP derivation and calibration relationships between biomass consumption, J. Geophys. Res., 110, D24311, doi:10.1029/2005JD006318, 2005.

Wooster, M. J., Roberts, G. J., Freeborn, P. H., Xu, W., Govaerts, Y., Beedy, R., He, J., and Mullen, R.: Meteosat SEVIRI Fire Radiative Power (FRP) products from the Land Surface Analysis Satellite Applications Facility (LSA SAF) - Part 1: Algorithms, product contents and analysis, Atmos. Chem. Phys. Discuss., 15, 15831-15907, doi:10.5194/acpd-15-15831-2015, 2015.

Xu, W., Wooster, M. J., Roberts, G., and Freeborn, P.: New GOES imager algorithms for cloud and active fire detection and fire radiative power assessment across North, South and Central America, Remote Sens. Environ., 114, 1876-1895, 2010.

Zhang, X., Kondragunta, S., Ram, J., Schmidt, C., and Huang, H.-C.: Near-real-time global biomass burning emissions product from geostationary satellite constellation, J. Geophys. Res., 117, D14201, doi:10.1029/2012JD017459, 2012. 